\title{
The Brand-Generated Content Interaction of Instagram Stories and Publications: A Comparison between Retailers and Manufacturers
}

\author{
Paloma de H. Sánchez-Cobarro ${ }^{1}$, Francisco-Jose Molina-Castillo ${ }^{2, *(1)}$ and \\ Cristina Alcazar-Caceres ${ }^{3}$ \\ 1 Departamento de Información y Documentación, University of Murcia, 30100 Murcia, Spain; \\ palomahenar.sanchez@um.es \\ 2 Departamento de Comercialización e Investigación de Mercados, University of Murcia, 30100 Murcia, Spain \\ 3 Bee Social, 30100 Murcia, Spain; cris@beesocialmedia.com \\ * Correspondence: fjmolina@um.es; Tel.: +34-868-8878-26
}

Received: 14 October 2020; Accepted: 25 November 2020; Published: 27 November 2020

\begin{abstract}
The last decade has seen a considerable increase in entertainment-oriented communication techniques. Likewise, the rise of social networks has evolved, offering different formats such as publication and stories. Hence, there has been a growing interest in knowing which strategies have the greatest social impact to help position organizations in the mind of the consumer. This research aims to analyze the different impact that stories and publications can have on the Instagram social network as a tool for generating branded content. To this end, it analyses the impact of the different Instagram stories and publications in various sectors using a methodology of structural equations with composite constructs. The results obtained, based on 800 stories and publications in four different companies (retailers and manufacturers), show that the reach of the story generally explains the interaction with Instagram stories. In contrast, in the case of publications, impressions are of greater importance in explaining the interaction with the publication. Among the main contributions of the work, we find that traditional pull communication techniques have been losing effectiveness in front of new formats of brand content generation that have been occupying the time in the relationship between users and brands.
\end{abstract}

Keywords: brand-generated content; social media; Instagram stories; Instagram publications; retailers; manufacturers

\section{Introduction}

Nowadays, nearly every company in the market is facing a strong competitive pressure due in part, to the impact of new technologies, but also to the need to change the way to communicate and promote products/services [1]. Social media has become an indispensable part of daily life, a means for creating assertive communication between brands and consumers [2] and is becoming a larger component of a firm's advertising budgets [3]. Companies, in all industries, are beginning to understand the possibilities that social media can offer and have changed their strategy towards how brands engage with and reach out to their customers [4]. For this reason, most every organization have evolved their approach to clients, moving from traditional one-to-many communication to a one-to-one system [5] that allows them to reach each client in a unique way [6]. In fact, during the last five years, advertising agencies, have found it more challenging to approach the public through conventional media [7]. Social networks have come to stay, and have become a new channel of communication for products [8]. However, they are here not only to communicate [9], but also to encourage the possibility of identifying 
and establishing regular, direct and customized interactions [10]. In this way, some social networks such as Instagram have changed their strategy. Nowadays, they are dedicated to informing or making companies' products known [11], and also have become a sales channel [12]. As a result, companies are exploring new techniques to generate content that not only inform but entertain consumers [13] to increase engagement [14] and, in turn, improve the consumer-brand relationships [15]. Therefore, the objective is not only that the consumer receives the message, but to stimulate the purchase intention to the product [16].

Unfortunately, it is challenging to integrate this new paradigm in the current situation, as consumers are facing advertising saturation [17] of traditional formats [18]. However, this also means an opportunity for new advertising formats, especially in social media networks [1]. Accordingly, several authors suggest that to improve the communication of the company with their potential consumers [19] it is crucial to create an advertisement which generates content that goes beyond passive communication [20] that traditionally have demonstrated to have a reduced impact on customer interactions [21]. Consumers may become aware of brands through social media in different ways, such as social media posts of friends or by brand-generated content from the firm [22] or with brand alliances [12]. In line with this argument, some authors [23] have suggested taking into account the general customer experience when assessing the marketing strategy in an online environment. The brand social campaigns carried out by the companies have made it possible to encourage continuous interaction between the consumer and the brand's history throughout the day [24]. This situation has improved the relationship between the consumer and the brand, and thus helps the marketing managers in the companies to guide and persuade consumers to buy products/services [25]. As a result, brand-generated content has been suggested as a clear strategy to overcome those limitations to communicate the products/services of the company [26] and achieve long-lasting bonds between the firm and the customer [27].

A clear example of brand-generated content in social media is the concept of Instagram "stories" and "publications" that has received great acceptance from both companies and customers [28]. Instagram stories can be considered as a modality that merges brand-generated content and entertainment [29]. For this reason, entertainment has played a fundamental role in the activity of social networks because it allows better penetration of the content in the life of the user [30]. In contrast to traditional publications, Instagram stories can amplify the brand message, producing "viralization" [31]. The key is that the brand-generated content of these stories must provide engaging entertainment or information, and in turn, offer a differential value for the recipient [32]. Some authors [23] argue that customer experience in an online environment goes beyond cognitive (informativeness) and instead should be directed to affective (entertainment) dimensions. We can observe how these advertising messages are being elaborated in such a way that the consumer is the one who looks for the content; entertainment is part of the message and brands become providers of experiences [33]. Some authors [25] have already proposed to investigate as future lines if a message portfolio can be consistent with a single brand strategy and what could be the impact on the interaction with it.

In summary, companies are continually looking for alternatives to attract customers to their brands and at the same time communicate the features of the products/services. However, still there are doubts about the usefulness of each type of format (story or publications) when sharing the message. To fill in these gaps, this research analyzes and compare the interaction of Instagram stories and publications based on reach and impressions for each of them. The idea is to maximize the impact in terms of social that could have for the company. The data used in this research comes from 800 publications/stories randomly selected from four firms (two retailers and two manufactures). The rest of the study is organized as follows. The first part analyses the literature on brand-generated content and Instagram. Following our theoretical model is proposed. In the third section, it is explained the methodology to carry out the study. Next, the main results obtained are described. Finally, the last section discusses the main limitations and future research guidelines that could be explored. 


\section{Instagram Publications/Stories and Brand-Generated Content in Social Media}

\subsection{Instagram Publications and Stories}

Since the introduction in 1997 of the first social media platform, the different platforms have attracted millions of users, becoming an integral part of their daily routines [6]. Social media can be defined as online applications, platforms and media which aim to facilitate interactions, collaborations and the sharing of content [4]. Some of the most relevant social media platforms are Facebook, Twitter and Instagram [11]. Instagram was launched in October 2010. During its first years, the app stood out for the quality of its filters and the aesthetics of the content that was uploaded-the social network of a beautiful range, where there was a lot of aesthetically pleasing content from territories like gastronomy and decoration. An exciting concept has emerged, called content engineering, which aims to develop advertising content that improves customer engagement [3]. In 2016, the stories were launched, in a format very similar to the "Snapchat" states, adding to the platform videos and images in a vertical form with a duration of $24 \mathrm{~h}$ in the network, and up to $15 \mathrm{~s}$ long. The era of "generalist ephemeral content" began. In the next years, it was launched the live video under the name Instagram Live, and other new publishing features such as galleries of up to 10 images. Finally, the most recent change on Instagram is the launch of Instagram TV (IGTV), a video channel with a maximum of 50 min in length. Additionally, being able to highlight stories to fix them and avoid their disappearance, the stories are beginning to be a fascinating tool for increasing their consumption exponentially. The personalization of the stories does not stop growing, from the beginning being able to add transparent background gifs (stickers), to the chat button, buy button or donation, to the most original filters to create different content, a very powerful tool for influencers and brands. The stories are used by 500 million users every day and of those, one third of the most viewed stories are professional (business) profiles. That is why 36\% of businesses use Instagram stories to promote their products or services with an average number of updates to Instagram stories of 2.3 stories per week. A detailed number of Instagram users by year is described in Figure 1.

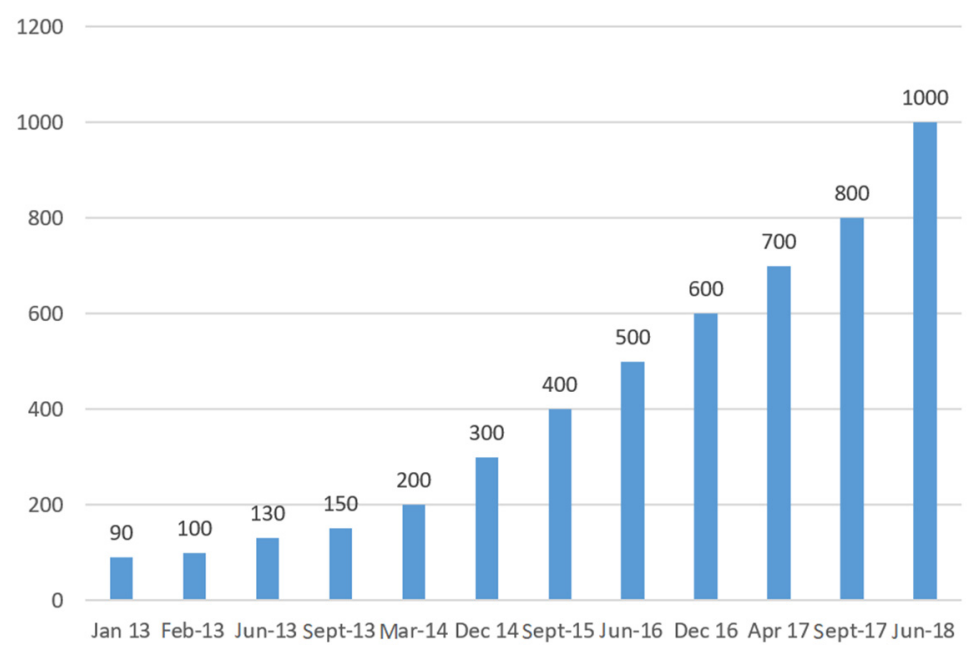

Figure 1. Instagram users from 2013 to 2018 (in millions). Sources Statista (2020).

\subsection{Instagram Shopping}

Social media is achieving more and more importance as a channel for gathering information about products and services by customers to help out in their purchase decision [21]. The Instagram shop is redefining what it means to shop online and transforming the outdated user journey from social media to store. Although Instagram is a social networking service first, it is also an up-and-coming e-commerce platform for big and small businesses alike. The latest innovation in shopping has provided many companies with an opportunity to showcase their products and more easily drive higher sales 
by completing a purchase without leaving the platform (HTTPS://WWW.SOCIALBAKERS.COM). In this case, the only thing the client has to do is to click on those contents that Instagram offers and they are automatically directed to the company's shop. With the new all-in-one storefront, users are presented with products in an entirely different fashion that is both simple and easy to use. As stated by Dabbous and Barakat [4], social media also plays an active role in influencing consumers' purchase decisions. According to IAB Spain (HTTPS:/IABSPAIN.ES), $24 \%$ of people who buy a product in social networks do it through the Instagram platform. Fifty-two percent of users who purchase products online do so because they have seen positive comments on social networks. According to the data of WWW.RETAILTOUCHPOINTS.COM, Instagram is the most influential social media platform when it comes to shopping. According to this, Instagram has a more decisive influence than other social media platforms such as Facebook, Twitter or Pinterest.

\subsection{Brand-Generated Content in Social Media}

Since the beginning of the 21st century, we can observe that, on the one hand, the forms of advertising communication have been evolving [34], the audience is much more fragmented [18], and the consumption of contents begins to migrate towards the digital world [35]. Social media platforms have evolved in recent years, from online channels to promote, share and participate in various activities, to become an increasingly important way for brands to communicate with consumers who become potential buyers of products and services [25]. According to Dabbous and Barakat [4], "companies have also transformed the way brand content is created, circulated, and consumed, giving consumers infinite opportunities for accessing brand information and using this information to make purchase decisions". It is interesting to note that, unlike traditional sales channels, customers evaluate products online not through physical interaction with the products, but through verbal and visual stimuli (design elements) that are transmitted by the brand [23]. Therefore, firms have invested in promoting their brands differently in social media such as encouraging brand-generated content of their product/services.

Brand-generated content has been described in many different ways in the literature, such as firm-generated content or marketer-generated content. In this research, we defined, in line with Kumar and Pansari [14], brand-generated content as "firm-initiated marketing communication in its official social media pages, which includes both promotional and non-promotional messages that go beyond generating short-term sales to help strengthen the bond between customers and firms". Thus, the landscape of brand management has been transformed, and promotional and branding activities must adapt to reach potential new customers [1]. In a very similar sense, Lehu [36] considers that it is a form of promotion that aims to create an emotional connection with customers and spread the message in a multimedia context. The objective is that the brand-generated content becomes an entertainment piece that is perfectly aligned with the attributes of the brand [13]. However, this concept goes beyond advertainment, covers other areas and includes other contents that are not only part of entertainment [26]. In an era where the message conveyed by the brand is so essential, marketers depend on their ability to design content that evokes experiences that go beyond the simple transmission of product information [23]. It is a challenge they must face to create content that entertains consumers and somehow resembles the experiences that could be lived in a traditional offline environment. Some authors [22] argue that brand messages that contain ample diagnostic information are more relevant for purchase intention than messages that rely on simplistic associations. As a result, brand-generated content consists of the integration of a brand into an entertainment, information or education content [37]. Accordingly, brand-generated content brings together a variety of content that addresses primarily to entertainment but can also include other topics related to cultural aspects.

\subsection{Interaction with the Brand in Social Media}

During many years everyone seems to have been excited with the "interactive revolution" in social media, but an interesting debate has arisen to define what interactivity means. The first 
conceptualizations around interactivity relied on user-machine interaction, in which the emphasis was on human interaction with computers. However, during the last years, the approach of interactivity from a user-message interaction perspective has gained attention [38]. Therefore, academics and managers alike are searching for the antecedents that motivate customer interactions with the message promoted by every brand [24]. Social media, as a communication medium, provides firms with the ability to communicate their products to the market and interact with the firm [10]. Some works in this field suggest that organizations initiatives should be directed to facilitate firm-customer interactions to foster emotional or psychological bonds between customers and firms [39]. To get the brand message to generate an interaction with the customer, it is crucial to take care of both the volume and the content of the messages that are published in social media platforms. According to this, it is essential to note that the message content of a publication frequently differs to the one included in a story that benefits from the use of video, audio, and pictures simultaneously [21]. Social media has stimulated new ways of interacting, defining new forms of communication, decision making and even shopping [21]. In fact, with appropriate customer engagement initiatives with the brand content, firms can influence the customers and, in turn, lead to increase firm sales [39]. During the last years, many studies have shown that advertising in social media can have an impact on customer behavior [8]. To achieve these goals, a firm will have to provide through the social media platform engaging content to inform, entertain and inspire, resulting in user advocates [10]. In the end, this content is the instrument that stimulates interactions, and therefore brands must publish exciting content to attract customers [21].

\section{Material and Methods}

\subsection{Research Questions and Theoretical Model}

Nowadays, individuals spend more time on Instagram than in any other social network platform [1]. As we have described in the previous sections, there is significant evidence that makes us think that the brand-generated content created by the stories and publications can have a meaningful impact on the interactions that are generated with the brand. Therefore, companies are aware of this situation and are redirecting their efforts to create more attractive messages to consumers. Firms often disseminate information such as new product launches through videos, images, and positive stories about their brands on social media [22]. Targeted marketing campaigns on Instagram can use different tools to get the customer to interact with the brand. While one company can emphasize its strategy in increasing the reach of its stories or publications, others can go further in highlighting the content in the impressions achieved by their stories or publications. Thus, when it comes to social media, these brands seem to be using a variety of message strategies. Therefore, the are two main questions that need to be answered: (1) What is the impact of story/publication reach in the interaction with the brand? (2) What is the impact of story/publication impressions in the interaction with the brand? Based on this, in Figure 2 we propose the following model to be tested:

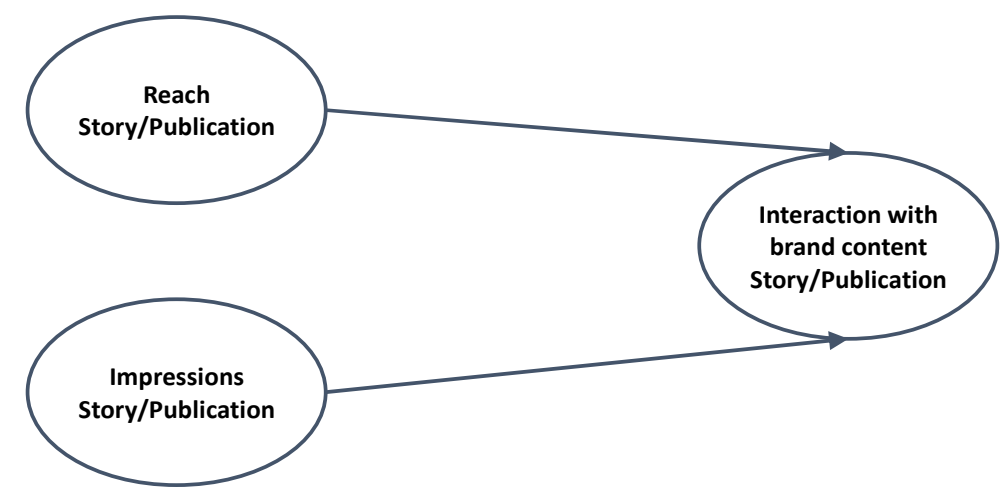

Figure 2. Theoretical model. 


\subsection{Data Collection}

The data in this work draw from a company in charge of managing the social networks of organizations in different sectors. Therefore, the research is based on objective data and not subjective assessments by users. To define the population under study, the researchers contacted a company in charge of managing the social networks of different companies. This company is one of the most well-known in his area with more than ten years of experience in the world of digital marketing and communication in Spain. The company works with various types of services in the field of online marketing, but mainly in the area of social networks and community manager for brands. In these ten years of experience, in addition to working with different types of customers, the company has evolved with constant training in social media and professional management tools. This acquired knowledge has allowed to carry out campaigns in an optimal way for customers and also innovate in the use of online tools. The company has received several awards in its sector and nowadays has six senior and two junior employees, but is in a constant progression and growth in both the number of clients and the company's turnover. It is essential to highlight that it has an average of 25 clients, both manufacturers and retailers, throughout the year. Among these projects, the management of the social networks of companies stands out, but also the realization of online events and development of web pages. The CEO collaborates actively in different mass media channels and is a reference in the sector of communication and online marketing in Spain, having been invited to significant conferences on social network management in different cities. Additionally, the CEO collaborates actively in training courses such as Google Activate, or webinars provided by Godaddy.

For eight weeks, interviews were conducted regularly with the CEO of the company and several questions raised about the most relevant factors of each company to select those that best fit the objective of the work. The results of these interviews were compared and contrasted with business reports and visits to the social networks of these companies as well as their respective websites. The objective was to select manufacturers and retailers' organizations that actively used social networks not only to publicize their products but also to encourage purchase through them. In the first step, four companies were selected, two related to retail distribution and two other companies related to the manufacture of products for the final consumer. The objective was to eliminate the bias that could be generated by delimiting the study in a single type of company. Once the companies were selected, the researchers analyzed from a qualitative point of view the peculiarities of each company, as well as the messages that conveyed the brand. In a second step, the team of researchers collected the data from the publications and stories of these companies during the year 2019. Thus, a total of 100 publications and 100 stories were randomly selected for each of the companies. The different publications and stories were randomly chosen to avoid bias. Still, a series of quotas were established so that these publications and stories would be evenly distributed throughout the year to prevent seasonal influence on the study results. For each of the observations, the research team distinguished whether it was based on a story or a publication and the extent to which there had been interaction with the content of each of them. This procedure made possible to have a database of 800 publications and stories. For each of these 800 observations, information was collected regarding the reach, impressions and interaction of the branded content generated by the company. Common method variance (CMV) is a frequent problem in survey studies [40], but it does not threaten our research due to the lack of single informant. Instead, all the information collected by researchers is based on objective data of what happened in the interaction with the story and publications of each brand. To preserve the confidentiality of the information, all data were anonymized, and each company was identified with a letter and a text to reflect its nature, distributor or manufacturer.

\subsection{Measures}

The measures from our study are based on objective observations. Thus, the reach of story/publication refers to the number of persons that have received the message. Impressions of story/publication indicate the number of times that each person has visualized the story/publication. 
Finally, interaction with the story/publication refers to whether the person has pressed in the story/publication to obtain further information. To test the proposed model of this work, we used a structural equation model based on the variance and the ADANCO 2.1 software [41]. This method uses a revolutionary way according to which a composite scale is generated for each of the constructions in our study. Unlike traditional approaches, which use reflexive or formative constructs [42], the method using composite constructs allows introducing quantitative and objective information from observations. In this way, the composite approach has emerged as an alternative way to eliminate the limitations offered by other forms of defining constructs. Unlike other methods, the composite approach does not contain any error terms for constructs, does not specify causality between constructs and indicators, and does not define co-variation between constructs and indicators [41].

\section{Results}

\subsection{Reliability}

To test the reliability of the model, we used the discrepancy between the empirical correlation matrix and that implemented by the model [41]. For this purpose, the model fit is determined by the standardized mean square residue (SRMR), which should not exceed the reference value of 0.08. [43]. In each of our eight models for story and publication, none of these values exceeded this value.

Discriminant validity is one of the most common threats of studies. Recent studies in this field $[44,45]$ suggest testing for the heterotrait-monotrait (HTMT) ratio. This technique has proven to be more effective over more traditional methods such as the confidence interval or AVE-correlation comparison test [45]. To calculate the HTMT ratio, it is necessary to compare the average correlations between constructs with the geometric mean of the average correlations of items within the same constructs. Our results proved that discriminant validity did not threaten our models as none of them exceeded the critical cut off value of 0.85 .

\subsection{Structural Model}

To test our model, we analyzed the relationships offered by the ADANCO software for each of the models. A trajectory coefficient shows the change in the dependent variable based on a difference in the independent variable while the rest of the constructions remain constant [41]. ADANCO uses the bootstrapping method to obtain the confidence intervals of the path value estimates. The results in Table 1 show a clear difference in the impact of the range and impressions on the stories and publications. As we can see in Table 1, if we analyze the case of the effect of the stories, impressions cannot be considered as an antecedent for the interaction with the content that retailers and manufacturers include in Instagram. However, we note that for the case of retailer firm B and manufacturer firm C, reach explains the interactions with content giving values of 0.69 (3.28) and 0.23 (4.52) respectively.

On the contrary, if we analyze the impact of the publications on the interaction with the contents of the companies studied, we observe different behavior. In this case, we observe that reach has no impact on the interaction on the four companies considered in the study. However, the impressions of the contents published in Instagram, are decisive to explain the interaction with the manufacturer firm $\mathrm{A}(0.61,4.87)$ and firm $\mathrm{C}(0.812 .44)$ and for the two retailers analyzed firm $\mathrm{B}(0.612 .54)$ and firm $\mathrm{D}$ (0.35 2.92). 
Table 1. Model results.

\begin{tabular}{|c|c|c|c|c|}
\hline & $\begin{array}{c}\text { Firm A } \\
\text { Manufacturer }\end{array}$ & $\begin{array}{l}\text { Firm B } \\
\text { Retailer }\end{array}$ & $\begin{array}{c}\text { Firm C } \\
\text { Manufacturer }\end{array}$ & $\begin{array}{l}\text { Firm D } \\
\text { Retailer }\end{array}$ \\
\hline & $\begin{array}{l}200 \text { Observations: } \\
100 \text { Stories and } \\
100 \text { Publications }\end{array}$ & $\begin{array}{l}200 \text { Observations: } \\
100 \text { Stories and } \\
100 \text { Publications }\end{array}$ & $\begin{array}{l}200 \text { Observations: } \\
100 \text { Stories and } \\
100 \text { Publications }\end{array}$ & $\begin{array}{l}200 \text { Observations: } \\
100 \text { Stories and } \\
100 \text { Publications }\end{array}$ \\
\hline \multicolumn{5}{|c|}{ Stories } \\
\hline Reach & n.s. & $0.69(3.28)^{* * *}$ & $0.23(4.52)^{* * *}$ & n.s. \\
\hline Impressions & n.s. & n.s. & n.s. & n.s. \\
\hline \multicolumn{5}{|c|}{ Publications } \\
\hline Reach & n.s. & n.s. & n.s. & n.s. \\
\hline Impressions & $0.61(4.87)^{* * *}$ & $0.61(2.54)^{* * *}$ & $0.81(2.44)^{* * *}$ & $0.35(2.92)^{* * *}$ \\
\hline
\end{tabular}

\section{Discussion}

From 2012 until today, the increase in entertainment actions has been progressive [13]. The educational, business, academic and informational fields have experienced a growing interest in brand-generated content. One of these new tools is Instagram's stories that allow consumers to interact with advertisers' content in an entertainment context, where brands offer entertainment and content with a high level of quality. In this way, Instagram stories provide the possibility to interact with content and the brand [46]. The brand-generated content strategically applied to Instagram stories helps advertisers to access their consumers more effectively, through engaging and suggestive content, which they want to access. In this sense, we have demonstrated that reach plays an essential role in explaining the interaction with the brand content generated by the firm. This new form of advertising content is also more versatile and dynamic [27] but also has its drawback as repeated impressions from stories do not guarantee interaction with the brand content generated by the firm. However, they do favor the link that the user establishes with the brand insofar as the user decides to select the display of one content against another. This research reinforces the need for organizations not only to be present on social networks due to the benefits they generate in terms of interaction, visibility and trust, but also to create the content of interest to their users, with which they can interact and whose publications in stories reinforce the publications and, therefore, the reach.

Brand strategies have evolved in recent years so that communication goes beyond the space provided by traditional media [33]. The Internet has allowed users to decide when, how and where they want to see content, as well as which content they want to share. The rejection by users of advertising content seriously damages the impact that brands should generate [17], and allow users more straightforward ways to avoid contact with unwanted advertising [47].

Today's consumers have been living with advertising for years, so that they know their records and, in many cases, flee from it, especially those who are better informed. Particularly, those who belong to more advanced sectors of society and have access to multiple sources through technology, and, therefore, consume on-demand content without interruption and advertising breaks [48]. The effectiveness of traditional advertising has been questioned for some years now. The scenario in which it is projected has been evolving, and communication goes beyond the space provided by traditional media, adopting multiple forms [8]. In this context, clients and users are defined according to their contact with the brand [21]. In the quest to understand consumer behavior, this research has investigated the impact of brand-generated content of Instagram stories and publications on social media interaction. Our results mostly confirm that the reach of stories is crucial to explain interaction, whether impressions determine publication interaction. And it is in this interaction that we have been able to see how publications take on a more significant role in the interaction with the consumer. This result confirms why it was relevant to be able to assess the impact of the story. In this study, we were able to demonstrate how 
stories and publications receive positive feedback, generating greater interactivity with the user and, therefore, greater scope for the brand.

In contrast, we have found that interactions with the publication are explained in a greater extent by the impressions in the customers. These results mark a trend that, while not a radical change, does require new forms and styles of communication for these publications to increase their effectiveness and that they can be adapted to their target audience. In this way, brands are encouraged to transmit their values by promoting a medium-term benefit [36] and improving the consumer experience in the long term and also its style and differentiating characteristics. This result again proves that most of the problems suffered by companies nowadays are due to the lack of proficiency by companies. We are facing an unprecedented saturation in the world of communication in social networks [11], and the big problem that conventional advertising has to face is its lack of recall [35]. To alleviate the difficulties suffered by advertising today is essential to rely on a firm with proved experience in managing social networks [24]. The design of the publications must be done meticulously to reach a more significant number of users that guarantee the interaction with the company.

The evolution in the insertion of content that companies are carrying out in recent years was already evident in the Annual study of Social Networks of IAB Spain (HTTPS://IABSPAIN.ES, which found that in 2016 there were 19 million people who used social networks in Spain. The increase has been so progressive that they have reached 26 million users in 2020. In this last year, data also show significant figures concerning Instagram as it is the second network (81\%) in frequency of use behind WhatsApp $(96 \%)$. However, Facebook continues to lead the number of users. Another relevant piece of data about this evolution is that one in three users consider that brands with social profiles generate greater trust. The access to be able to interact with the brands is mainly focused on customer service, that is, the user perceives the proximity of the company, being the most followed sectors those that provide the user with information about entertainment, culture and media. In this study, being aware that the data cannot be extrapolated to the vast universe of retail or manufacturing, it is possible to perceive how the impressions present a higher level of connectivity with the user, even though the scope may be similar. Being the results of the impressions in firm A and B similar, there is an essential variation of the levels of significance. Besides, the firms $C$ and D, present a significant and minor result respectively, to the two previous ones. This result leads us to consider in the future the increase in the volume of manufacturer and retailer companies, and it is also possible to have stories or publications per company. However, the result is more influenced by the differences in the behavior of the printing of the publications than in the number of them. The variations mentioned above also affect the fact that there may be a quantitative imbalance that can be supported by a quantum analysis of the content of the stories and publications to obtain more data that would allow us to make a more precise assessment of the scope and the impressions.

While it is true that it is demonstrated that both new forms of communication, stories and publications, not only attracts but also suggests or proposes a way of living the brand universe, as opposed to the push communication of the mass media.

It is necessary to emphasize the importance of this qualitative leap. The traditional media are not technically capable of offering the user a direct interaction at the moment the user is willing to do it, and they cannot adapt to users' needs, time, pace, and even geographical position [9]. However, social networks, and in particular, Instagram, as we have seen, respond through their stories and publications to users' demands for content. Advertisers consider that it plays a decisive role in their global strategy, and their knowledge of the multiple possibilities it offers, to entertainment, makes it increasingly popular [10]. The search for engagement, brand image and notoriety continue to be the values most emphasized by advertisers, and they are also involved in the development of the actions.

This research contributes to understanding the qualitative and quantitative leap that is gradually taking place in the behavior of consumers and companies when it comes to establishing interrelations [39]. This study helps to provide answers to how social media is a choice to increase the effectiveness of a promotional or advertising activities and in particular how stories and publications 
favor their dissemination and interactivity with the consumer, through the evaluation of impressions and reach. This information can be valuable for advertisers, companies and community managers who face the challenge of establishing strategies to bring their products and services closer to users with a limited budget and conditioned by the set objectives.

\section{Limitations and Future Research}

The authors acknowledge that their research has limitations. First, we have adopted a firm perspective to analyze the impact of Instagram stories in social media effectiveness. Therefore, we have focused on brand content generated by the company [49], but it will be interesting to explore the impact of user-generated content of Instagram stories and publication [47]. Accordingly, it could be attractive to adopt a dyadic approach to combine our findings with self-response opinions of customers [16]. This suggestion will also help to clarify why the reach of the story did not have a significant relationship for two of the companies. Other remarkable future research lines could be explored. It is generally accepted that the strategic planning of advertising communication no longer responds to traditional canons [50]. Therefore, to establish long-term relationship patterns with audiences, it will be advisable to analyze in greater depth how leisure and entertainment could redefine not only a one-time purchase but also long-term consumer relations [1]. At the same time, it is a priority to consider if existing formats fit new social media channels and explore other possibilities offered by digital environments [15]. Undoubtedly, a more profound analysis of these topics will guarantee the success of advertising actions of companies.

Author Contributions: Conceptualization and discussion were elaborated by P.d.H.S.-C.; methodology and results were elaborated by F.-J.M.-C.; theoretical background was elaborated by F.-J.M.-C. and C.A.-C. All authors have read and agreed to the published version of the manuscript.

Funding: This research received no external funding.

Acknowledgments: The authors greatly appreciated the comments of reviewers to improve this research.

Conflicts of Interest: The authors declare no conflict of interests.

\section{References}

1. Ilich, K.L.; Hardey, M. 'It's all about the packaging': Investigation of the motivations, intentions, and marketing implications of sharing photographs of secondary packaging on Instagram. Inf. Commun. Soc. 2020, 23, 1-19. [CrossRef]

2. Demiray, M.; Burnaz, S. Exploring the impact of brand community identification on Facebook: Firm-directed and self-directed drivers. J. Bus. Res. 2019, 96, 115-124. [CrossRef]

3. Lee, D.; Hosanagar, K.; Nair, H.S. Advertising content and consumer engagement on social media: Evidence from facebook. Manag. Sci. 2018, 64, 5105-5131. [CrossRef]

4. Dabbous, A.; Barakat, K.A. Bridging the online offline gap: Assessing the impact of brands' social network content quality on brand awareness and purchase intention. J. Retail. Consum. Serv. 2020, 53, 101966-101976. [CrossRef]

5. Hoffman, D.; Fodor, M. Can you measure the roi of your social media marketing? MIT Sloan Manag. Rev. 2010, 52, 41 .

6. Cvijikj, I.P.; Michahelles, F. Understanding the user generated content and interactions on a Facebook brand page. Int. J. Soc. Humanist. Comput. 2013, 2, 118-140. [CrossRef]

7. Wang, Z.; Kim, H.G. Can Social Media Marketing Improve Customer Relationship Capabilities and Firm Performance? Dynamic Capability Perspective. J. Interact. Mark. 2017, 39, 15-26. [CrossRef]

8. Mochon, D.; Johnson, K.; Schwartz, J.; Ariely, D. What are likes worth? a facebook page field experiment. J. Mark. Res. 2017, 54, 306-317. [CrossRef]

9. Rutz, O.J.; Bucklin, R.E. From generic to branded: A model of spillover in paid search advertising. J. Mark. Res. 2011, 48, 87-102. [CrossRef]

10. Nisar, T.M.; Prabhakar, G.; Ilavarasan, P.V.; Baabdullah, A.M. Up the ante: Electronic word of mouth and its effects on firm reputation and performance. J. Retail. Consum. Serv. 2020, 53. [CrossRef] 
11. Smith, A.N.; Fischer, E.; Yongiian, C. How does brand-related user-generated content differ across youtube, facebook, and twitter? J. Interact. Mark. 2012, 6, 102-113. [CrossRef]

12. Kupfer, A.-K.; der Holte, N.P.v.; Kübler, R.V.; Hennig-Thurau, T. The Role of the Partner Brand's Social Media Power in Brand Alliances. J. Mark. 2018, 82, 25-44. [CrossRef]

13. Hwang, J.; Choi, L. Having fun while receiving rewards?: Exploration of gamification in loyalty programs for consumer loyalty. J. Bus. Res. 2020, 106, 365-376. [CrossRef]

14. Kumar, V.; Pansari, A. Competitive Advantage through Engagement. J. Mark. Res. 2016, 53, 497-514. [CrossRef]

15. Gorlier, T.; Michel, G. How special rewards in loyalty programs enrich consumer-brand relationships: The role of self-expansion. Psychology \& Marketing 2020, 37, 564-577. [CrossRef]

16. de Vries, L.; Gensler, S.; Leeflang, P.S.H. Rffects of traditional advertising and social messages on brand-building metrics and customer acquisition. J. Mark. 2017, 81, 1-15. [CrossRef]

17. Yuki, T. What Makes Brands' Social Content Shareable on Facebook? An Analysis that Demonstrates the Power of Online Trust and Attention. J. Advert. Res. 2015, 55, 458-470. [CrossRef]

18. Kaplan, A.M.; Haenlein, M. Users of the world, unite! The challenges and opportunities of Social Media. Bus. Horiz. 2010, 53, 59-68. [CrossRef]

19. Maity, M.; Gupta, S. Mediating effect of loyalty program membership on the relationship between advertising effectiveness and brand loyalty. J. Mark. Theor. Pract. 2016, 24, 462-481. [CrossRef]

20. Dhar, V.; Chang, E.A. Does Chatter Matter? The Impact of User-Generated Content on Music Sales. J. Interact. Mark. 2009, 23, 300-307. [CrossRef]

21. Sabate, F.; Berbegal-Mirabent, J.; Cañabate, A.; Lebherz, P.R. Factors influencing popularity of branded content in Facebook fan pages. Eur. Manag. J. 2014, 32, 1001-1011. [CrossRef]

22. Colicev, A.; Malshe, A.; Pauwels, K.; O'Connor, P. Improving consumer mindset metrics and shareholder value through social media: The different roles of owned and earned media. J. Mark. 2018, 82, 37-56. [CrossRef]

23. Bleier, A.; Harmeling, C.M.; Palmatier, R.W. Creating Effective Online Customer Experiences. J. Mark. 2018, 83, 98-119. [CrossRef]

24. Stephen, A.T.; Galak, J. The effects of traditional and social earned media on sales: A study of a microlending marketplace. J. Mark. Res. 2012, 49, 624-639. [CrossRef]

25. Ashley, C.; Tuten, T. Creative strategies in social media marketing: An exploratory study of branded social content and consumer engagement. Psychol. Mark. 2015, 32, 15-27. [CrossRef]

26. Goh, K.-Y.; Heng, C.-S.; Lin, Z. Social media brand community and consumer behavior: Quantifying the relative impact of user-and marketer-generated content. Inf. Syst. Res. 2013, 24, 88-107. [CrossRef]

27. Chaabane, A.M.; Pez, V. Make me feel special: Are hierarchical loyalty programs a panacea for all brands? The role of brand concept. J. Retail. Consum. Serv. 2017, 38, 108-117. [CrossRef]

28. Kusumasondjaja, S.; Tjiptono, F. Endorsement and visual complexity in food advertising on Instagram. Internet Res. 2019, 29, 659-687. [CrossRef]

29. de Veirman, M.; Hudders, L. Disclosing sponsored Instagram posts: The role of material connection with the brand and message-sidedness when disclosing covert advertising. Int. J. Advert. 2020, 39, 94-130. [CrossRef]

30. Rehnen, L.-M.; Bartsch, S.; Kull, M.; Meyer, A. Exploring the impact of rewarded social media engagement in loyalty programs. J. Serv. Manag. 2017, 28, 305-328. [CrossRef]

31. Arora, A.; Bansal, S.; Kandpal, C.; Aswani, R.; Dwivedi, Y. Measuring social media influencer index- insights from facebook, Twitter and Instagram. J. Retail. Consum. Serv. 2019, 49, 86-101. [CrossRef]

32. Song, Y.-A.; Lee, S.Y.; Kim, Y. Does mindset matter for using social networking sites?: Understanding motivations for and uses of Instagram with growth versus fixed mindset. Int. J. Advert. 2019, 38, 886-904. [CrossRef]

33. Thelander, A.; Cassinger, C. Brand New Images? Implications of Instagram Photography for Place Branding. Media Commun. 2017, 5, 6-14. [CrossRef]

34. Vinhas, A.S.; Bowman, D. Online/offline information search patterns and outcomes for services. J. Serv. Mark. 2019, 31, 753-770. [CrossRef]

35. Mayar, V.; Ramsey, G. Digital Impact: The Two Secrets to Online Marketing Success; John Wiley \& Sons: Hoboken, NJ, USA, 2011.

36. Lehu, J. Branded Enterntainment; Kogan Page: London, UK, 2007. 
37. Malhotra, A.; Malhotra, C.K.; See, A. How to Create Brand Engagement on Facebook. MIT Sloan Manag. Rev. 2013, 54, 18-20.

38. Liu-Thompkins, Y.; Shrum, L.J. What is interactivity and is it always such a good thing? implications of definition, person, and situation for the influence of interactivity on advertising effectiveness. J. Advert. 2002, 31, 53-64.

39. Meire, M.; Hewett, K.; Ballings, M.; Kumar, V.; van den Poel, D. The role of marketer-generated content in customer engagement marketing. J. Mark. 2019, 83, 21-42. [CrossRef]

40. Podsakoff, P.M.; MacKenzie, S.B.; Lee, J.-Y.; Podsakoff, N.P. Common method biases in behavioral research: A critical review of the literature and recommended remedies. J. Appl. Psychol. 2003, 88, 879-903. [CrossRef]

41. Henseler, J. Bridging Design and Behavioral Research With Variance-Based Structural Equation Modeling. J. Advert. 2017, 46, 178-192. [CrossRef]

42. Jarvis, C.; Mackenzie, S.; Podsakoff, P. A Critical Review of Construct Indicators and Measurement Model Misspecification in Marketing and Consumer Research. J. Consum. Res. 2003, 30, 199-218. [CrossRef]

43. Hu, L.; Bentler, P.M. Cutoff criteria for fit indexes in covariance structure analysis: Conventional criteria versus new alternatives. Struct. Equ. Model. A Multidiscip. J. 1999, 6, 1-55. [CrossRef]

44. Henseler, J.; Ringle, C.M.; Sarstedt, M. A new criterion for assessing discriminant validity in variance-based structural equation modeling. J. Acad. Mark. Sci. 2014, 43, 115-135. [CrossRef]

45. Voorhees, C.M.; Brady, M.K.; Calantone, R.; Ramirez, E. Discriminant validity testing in marketing: An analysis, causes for concern, and proposed remedies. J. Acad. Mark. Sci. 2015, 44, 119-134. [CrossRef]

46. Apiraksattayakul, C.; Papagiannidis, S.; Alamanos, E. Shopping via Instagram: The Influence of Perceptions of Value, Benefits and Risks on Purchase Intentions. Int. J. Online Mark. 2017, 7, 1-20. [CrossRef]

47. Fu, D.; Hong, Y.; Wang, K.; Fan, W. Effects of membership tier on user content generation behaviors: Evidence from online reviews. Electron. Commer. Res. 2018, 18, 457-483. [CrossRef]

48. Kanuri, V.K.; Chen, Y.; Sridhar, S. Scheduling content on social media: Theory, evidence, and application. J. Mark. 2018, 82, 89-108. [CrossRef]

49. Kumar, A.; Bezawada, R.; Rishika, R.; Janakiraman, R.; Kannan, P.K. From social to sale: The effects of firm-generated content in social media on customer behavior. J. Mark. 2016, 80, 7-25. [CrossRef]

50. Kim, T.; Barasz, K.; John, L.K. Why Am I Seeing This Ad? The Effect of Ad Transparency on Ad Effectiveness. J. Consum. Res. 2019, 45, 906-932. [CrossRef]

Publisher's Note: MDPI stays neutral with regard to jurisdictional claims in published maps and institutional affiliations.

(C) 2020 by the authors. Licensee MDPI, Basel, Switzerland. This article is an open access article distributed under the terms and conditions of the Creative Commons Attribution (CC BY) license (http://creativecommons.org/licenses/by/4.0/). 